\title{
John, o Selvagem: aspectos de um personagem pícaro em Admirável Mundo Novo, de Aldous Huxley
}

\section{John, the Savage: aspects of a picaro character in Brave New World, by Aldous Huxley}

\section{Cláudio Marcos VELOSO JÚNIOR* \\ UEL}

\section{Luiz Carlos Migliozzi Ferreira de MELLO** $U E L$}

Resumo: Baseado em A Saga do Anti-Herói, um estudo sobre picaresca de Mario González e as observações de Antonio Candido em Dialética da Malandragem, esse estudo analisará o personagem John em Admirável Mundo Novo, de Aldous Huxley, procurando evidenciar aspectos que permitem aproximar esse personagem a um personagem pícaro. Primeiramente, o estudo fará determinados levantamentos críticos a respeito da origem e dos elementos existente no gênero pícaro para, em seguida, analisar John evidenciando nele traços semelhantes a de um personagem pícaro.

Palavras-chave: Personagem Pícaro. Admirável Mundo Novo. Aldous Huxley.

Abstract: Based on A Saga do Anti-Herói, a study of picaresque Mario González and the observations of Antonio Candido in Dialética da Malandragem, this study will examine the character John in Brave New World, by Aldous Huxley, searching to highlight aspects that allow approaching this character to a picaro character. First of all, the study will do certain critical surveys regarding the origin and the existing elements in the picaresque genre for, afterwards, analyzing John showing similar traits to a picaro character.

Keywords: Picaro Character. Brave New World. Aldous Huxley.

\author{
*Aluno do programa \\ de pós-graduação \\ da Universidade \\ Estadual de Londrina. \\ E-mail: claudio- \\ veloso@uol.com.br \\ ** Doutor em Semiótica \\ e Lingüística Geral. \\ Professor efetivo da \\ Universidade Estadual \\ de Londrina
}




\section{Introdução}

Aldous Huxley figura em Admirável Mundo Novo uma sociedade futurista comandada pelo cientificismo. A sociedade, denominada Londres, situada aproximadamente no ano de 2.495, é composta por indivíduos que vivem em constante harmonia, fazendo com que essa sociedade aparente não ter conflitos, o que causa a impressão que o romance se trata de uma utopia. Entretanto, durante a narrativa, percebe-se que a utopia não é totalmente concreta, por ser exposto que os indivíduos são, desde nascença, obrigados a aceitarem suas funções sociais e a realizarem atividades determinadas socialmente, verificando-se, assim, uma manipulação social, que torna os sujeitos alienados.

No contexto da narrativa, é inserida uma outra sociedade, denominada Malpaís, localizada no Novo México. Essa, por sua vez, é afastada da sociedade de Londres e não segue as mesmas regras que a outra. Os indivíduos que vivem em Malpaís são considerados selvagens. Nesse local está John. Esse personagem é diferente dos demais por seus atos e ideologia não serem semelhantes aos exigidos socialmente.

É em John que esse estudo irá focar. Fazendo um paralelo entre esse personagem e aspectos existentes no gênero pícaro, esse estudo intenciona expor traços em John semelhantes a de um personagem picaresco. Não há pretensão de elencar o personagem a categoria de pícaro, mas sim fazer uma aproximação desse personagem aos do gênero em questão.

Em um primeiro momento, esse estudo fará determinados levantamentos críticos a respeito da origem e dos elementos existentes no gênero pícaro, assim como também sua evolução histórica. Em seguida, o estudo evidenciará aspectos existentes em personagens pícaros procurando relacionar como esses aspectos aparecem em John. De conclusão, com base no que foi relatado, abordará se John se enquadra a categoria de personagem pícaro ou se apenas possui traços desse tipo de personagem. Pretende-se, também, diferenciar o que faz dele um anti-herói e não um herói. Serão utilizados como base teórica os estudos sobre picaresca de Mario González, expostos em A Saga do Anti-Herói, e de Antonio Candido, em A dialética da Malandragem.

\section{Gênero Pícaro: a origem e seus principais elementos:}

Mario González (1994) relata que, entre a segunda metade do século XVI e a primeira do século XVII, surge na Espanha uma nova forma narrativa. O teórico afirma que essa nova forma narrativa é que dará início ao que denominamos de "Romance Picaresco". Ele ressalta que nesse período destacam-se três romances: $O$ Lazarilho de Tormes, Guzmán de Alfarcha e $O$ Buscão. 
González (1988) expõe que no dicionário Novo Aurélio o termo picaresco é denominado como sinônimo de burlesco, cômico e ridículo. No entanto, o pesquisador alerta que esse uso do termo não tem a ver com "o que o termo evoca quando usado em relação ao gênero literário tradicional”.

González (1994) alerta para o fato de que séculos depois

do aparecimento do primeiro romance picaresco não haja um consenso sobre o gênero e, muito menos, uma definição clara do que se possa entender por romance picaresco. Consequentemente, tampouco há acordo sobre a extensão histórica do termo.

Para González (1994), para um romance se enquadrar ao gênero pícaro deve-se conter e apoiar-se em três elementos: “o antí-herói denominado pícaro, seu aventureiro projeto de ascensão social pela trapaça e a sátira social traçada na narração desse percurso”. Sobre o primeiro elemento desse tripé, Massaud Moisés (2004) expõe que “o pícaro pode ser considerado um anti-herói [...] Mas há quem o julgue ser um herói”.

Tratando-se da análise desse gênero, González (1988, p.40) destaca dois elementos que se deve atentar para entender o romance picaresco:

Primeiro, o aspecto histórico da modalidade, que leva a que devamos entendê-la como um processo. [...] Em segundo lugar, entendermos que deve ser evitado o erro de se ver no romance picaresco a narrativa de uma única fábula com pequenas variantes; ou o de limitar o discurso picaresco a uma estreita receita sem alternativa. Pelo contrário, achamos que toda conceituação de 'picaresca' há de atender à integração de um certo tipo de história num certo tipo de discurso.

A obra ter um caráter biográfico é considerado um outro elemento necessário para enquadrar o romance ao gênero pícaro. Com isso, González (1994) aponta que, inicialmente, para considerar um romance a esse gênero era necessário que a narrativa fosse em primeira pessoa, visto que o uso dessa forma narrativa dá caráter autobiográfico a obra. Candido (1970) afirma que ao próprio pícaro narrar suas aventuras cria "um dos encantos para o leitor, transmitindo uma falsa candura que o leitor cria habilmente e já é recurso psicológico de caracterização”.

González coloca que a escolha da primeira pessoa se deu por causa de os primeiros romances pícaros utilizarem esse tipo de narrativa, como é o caso de $O$ Lazarilho de Tormes e Guzmán de Alfarache. Sobre esse aspecto, ele reflete:

Do modelo constituído pelas duas obras anteriores origina-se o uso da narrativa de primeira pessoa para exposição da autobiografia. No entanto, há diferenciações que devem ser consideradas. Por um lado, se não há 
digressões moralizantes ao estilo de Guzmán de Alfaroche, isso não impede a presença de textos alheios à autobiografia incorporados por outros narradores (GONZÁLEZ, 1994, p.189).

Diante disso, o mesmo pesquisador chama atenção para o fato que, “ao longo do tempo, o narrador de primeira pessoa foi substituído, eventualmente, pelo de terceira” (GONZÁLEZ, 1994, p.265) e coloca que

para muitos, a autobiografia é imprescindível. Mais ainda, alguns críticos chegam ao ponto de exigir determinada coerência no tratamento da forma autobiográfica, o que leva, no caso de Francisco Rico, a reduzir o gênero, ao menos em suas manifestações esteticamente válidas, a duas obras, como já vimos: Lazarillo de Tormes e Guzmán de Alfachez (GONZÁLEZ, 1994, p.263).

González (1994) relata ainda que “o romance picaresco reaparece no século XX”. O teórico acrescenta que

ao chegar ao século $\mathrm{XX}$, os novos pícaros protagonizarão relatos nos quais estarão presentes novas formas de se apresentar o testemunho da realidade, sem que seja imprescindível o narrador de primeira pessoa, ou mediante formas narrativas que preservem o ponto de vista do protagonista (GONZÁLEZ, 1994, p.266).

Essa transformação não rompeu com o gênero picaresco, apenas causou "mudanças mais drásticas por estarem contextualizadas em outra circunstância histórica” (GONZÁLEZ, 1994, p.266). Aos romances picarescos que se inserem nessa transformação, González (1994) os nomeia de neopicaresca, mas alerta para o fato de que essas obras continuarão a caber na definição de romance pícaro.

\section{Traços de um personagem pícaro em John, o Selvagem}

Realizado esse breve levantamento, o estudo parte para o seu segundo momento: expor certos pontos de Admirável Mundo Novo, de Aldous Huxley, focalizando aspectos que aproximem John de um personagem pícaro.

John, o selvagem, não conta sua própria história, "sob este aspecto o herói é um personagem como os outros, apesar de preferencial” (CANDIDO, 1970, p.68). John, é um rapaz religioso, filho de Linda, uma mulher que era de Londres, mas que em uma visita a Malpaís ficou perdida e, a partir disso, não conseguiu mais voltar a seu local de origem. Durante a narrativa, é evidenciado que junto com Linda, em Malpaís, estava Tomakin, o qual exerce o cargo de diretor e é o pai de John: 
- Tive a mesma ideia que o senhor - dizia o Diretor. - Eu queria ver os selvagens. Obtive uma autorização para ir ao Novo México e lá fui durante minhas férias de verão. Acompanhado da moça com quem eu andava naquela ocasião; Era uma Beta-Menos e creio...- fechou os olhos - creio que tinha cabelos louros. Em todo caso, era pneumática, excepcionalmente pneumática; disso me recordo. Pois bem, nós fomos, observamos os selvagens, passeamos a cavalo e tudo mais. E então - foi quase no fim da minha licença -; e então, bem ela se perdeu (HUXLEY, 2009, p.157)

Adentrando na análise dos traços pícaros em John, ressalta-se, de início, a característica de um indivíduo isolado. González (1994) expõe a visão de Blanco Aguinaga de que o pícaro é: “um vagabundo solitário e na sua solidão descobre a mentira dos demais pontos de vista, conquistando, assim, a superioridade que lhe permite julgar e condenar os outros”.

González (1994) não concorda totalmente com o pensamento de Aguinaga porque, para ele, o pícaro não é “um vagabundo, mas alguém à procura de um emprego que o reintegrasse à sociedade” e que, além disso, "não seria um aventureiro, mas um homem que, devido à crise, perdeu sua estabilidade; seu objetivo seria recuperar essa estabilidade e abandonar a vida picaresca”.

A solidão de John se fundamenta pelo fato da personagem não possuir aceitação social: "Em todo caso, parece que John a contraiu com índios. Porque, naturalmente, convivia muito com eles. Embora tenham sido sempre muito maus com ele, não o deixando fazer o que as outras crianças faziam” (HUXLEY, 2009, p.192).

Reiterado a isso, está o fato de John ser desprezado pela própria mãe Linda:

Eu não sou tua mãe! Não quero ser tua mãe! - Mas, Linda...Oh! - Ela deu-lhe uma bofetada. - Transformada numa selvagem! - vociferou. - Tendo filhos como um animal!... Se não fosse por tua causa, eu poderia ter ido procurar o Inspetor, poderia ter saído daqui. Mas não com um bebê. Teria sido vergonhoso demais (HUXLEY, 2009, p.200).

Isso faz com que o próprio personagem se considere um indivíduo solitário:

Só, sempre só - dizia o jovem. Essas palavras despertam um eco doloroso no espírito de Bernard, só, só... - Eu também - respondeu, num impulso confidencial. - Terrivelmente só - Você também? - John mostrou-se surpreso. (HUXLEY, 2010, p.213).

E, assim como um personagem pícaro, tem o objetivo de procurar por sua estabilidade. Sobre o estado de origem de John, esse é de precariedade. O personagem vive em Malpaís, como foi relatado, um lugar afastado da cidade: 
John ficou sabendo que 'uma Reserva de Selvagens é um lugar que, devido a condições climáticas ou geológicas desfavoráveis, ou à pobreza de recursos naturais, não compensa as despesas necessárias para civilizá-lo”. (HUXLEY, 2009, p.252).

A sujeira está presente nesse lugar: "Lá fora, no meio da poeira e do lixo - havia agora quatro cães -, Bernard e John caminhavam lentamente de um lado para outro” (HUXLEY, 2009, p.195). A precariedade pode ser observada até mesmo na caracterização da mãe de John:

Às vezes, durante dias, Linda nem sequer se levantava. Ficava na cama, mergulhada em tristeza. Ou então bebia o líquido que Popé trazia, ria muito e adormecia. Algumas vezes vomitava. Com frequência esquecia-se de banhá-lo e não havia nada que comer, a não ser tortilhas frias... Lembravase da primeira vez em que ela achara aqueles bichinhos nos seus cabelos, como ela gritara, gritara. (HUXLEY, 2009, p.200)

Nesse contexto, esses dois aspectos podem ser observados como representação de pobreza. Isso faz com que John se enquadre na concepção de Maraval, exposta por González (1994), de que “o pícaro é um 'pobre’, no amplo sentido”.

Antonio Candido (1970) expõe que o personagem pícaro “vive um pouco ao sabor da sorte, sem plano nem reflexão”. A sorte irá aparecer para John no momento em que ele se depara com a proposta, vinda do personagem Bernard Marx, de conhecer uma sociedade diferente da dele. Além de John, Marx tem o interesse também em levar Linda a Londres.

John simpatiza com Marx por ambos se considerarem indivíduos isolados. Essa simpatia de John com Marx cria um vínculo de confiança entre os dois. Isso influencia John aceitar, sem ter conhecimento pleno desse outro local, a proposta de Marx em conhecer outra sociedade.

A atração em entrar em contato com outro lugar se dá por essa ser uma oportunidade de ele se reintegrar socialmente. Mantendo-se em Malpaís, ele continuará em um estado de mal-estar por ser isolado nesse lugar. Constata-se, com isso, que o personagem age pensando em si mesmo e ao agir assim se relaciona com o mesmo interesse dos personagens pícaros, como González (1994) ressaltou.

A sociedade que John tem a oportunidade de conhecer é Londres, sociedade de origem de Bernard Marx. Por Londres tratar-se de uma metrópole, John ocupará o espaço ideal para o pícaro: “a cidade é o espaço das relações humanas adequadas e até necessárias para a picaresca” (GONZÁLEZ, 1994, p.74). Lembrando que para Candido (1970, p. 68) "na origem o pícaro é ingênuo”, constata-se, nesse momento, a ingenuidade de John, já que o personagem aceita ir a um lugar que ele conhece só com base apenas no que lhe foi relatado: 
Histórias estranhas, tanto mais maravilhosas para ele porque eram contadas por meio daquelas outras palavras e, por isso, não completamente entendidas. Deitado na cama, ele pensava no Céu e em Londres (HUXLEY, 2009, p.202).

A ingenuidade de John é reiterada por ele não perceber a real intenção de Marx em levá-lo a Londres. Bernard Marx é um indivíduo que sofre preconceito em sua sociedade de origem. O preconceito ocorre porque Marx não possui características físicas iguais aos demais sujeitos e não aceitar praticar as atividades determinadas socialmente. Com isso, ele é evitado, causando assim a sensação de ser uma pessoa solitária.

Bernard Marx cria interesse em conhecer a sociedade de Malpaís por ser um espaço desvinculado das regras sociais de Londres. Ao entrar em Malpaís, Marx entra em contato com John e o manipula a ir a outra sociedade. Ele tem ciência que a mãe de John era de Londres e, além disso, sabe que Linda estava com o diretor em Malpaís. Dessa forma, Bernard deduz que John é filho do diretor. Tomakin ocupa um cargo superior ao de Marx. O interesse de Marx em trazer John e a mãe dele a cidade é para fazer o diretor passar por um vexame e assim deixar o cargo que ele ocupa:

A fim de que seu castigo possa servir aos melhores interesses da Sociedade, o mais afastado possível de todo o Centro populacional importante. $\mathrm{Na}$ Islândia ele terá muito poucas oportunidades de desencaminhar os outros com seu exemplo antifordiano - O Diretor calou-se um instante; depois, cruzando os braços, voltou-se com ar imponente para Bernard. - Marx disse -, pode apresentar alguma razão para que eu não execute neste instante a sentença que acaba de ser pronunciada contra o senhor? - Sim, posso - respondeu Bernard, em voz muito alta. [...] Linda adiantou-se, sorrindo coquetemente seu sorriso desdentado e descolorido [...] - Ali está ele - disse apontando para o Diretor - Pensou que não o reconheceria? - perguntou Linda indignada. Depois, voltando-se para o Diretor [...] Mas sou eu Linda; sou eu, Linda - Sua voz foi abafada pelos risos. - Você me fez ter um bebê - gritou, dominando o tumulto (HUXLEY, 2009, p.235-27).

Além disso, Marx utiliza John para conseguir aceitação social:

Os dias passaram. O êxito subiu à cabeça de Bernard como um vinho capitoso e reconciliou-se completamente - como deve fazê-lo um bom produto inebriante - com um mundo [...] Porque o fato de criticar exaltava nele o sentimento de sua importância, dava-lhe a impressão de ser maior - Ao mesmo tempo, agradava-lhe genuinamente ter sucesso e possuir todas as mulheres que quisesse. (HUXLEY, 2009, p.246).

González (1994) expõe que o personagem pícaro "pode ser levado a refletir, mas essas reflexões sempre significarão uma consideração sobre a própria situação”. John, devido a sua ingenuidade, não percebe que Bernard 
Marx o utiliza como objeto. Assim como um pícaro, chega o momento que John começa a refletir sobre sua própria situação A partir do momento em que compreende que Marx o está usando, ele deixa de cooperar:

Bernard teve de gritar através da porta fechada a chave; o Selvagem não queria abrir. - Mas todos estão lá esperando por você. - Que esperem - foi a resposta que veio em voz abafada. - Mas você sabe muito bem, John -como é difícil ser persuasivo falando em altos brados- -, que eu os convidei expressamente para conhecê-lo. - Devia ter perguntado primeiro a mim se queria conhecê-los (HUXLEY, 2009, p.267).

Dessa forma, John vai deixando seu estado de ingenuidade. Seu interesse de conhecer um lugar diferente do seu resulta em uma frustração e em uma desilusão por não condizer com a sua expectativa.

González (1994) explica que no romance picaresco: “O protagonista vai do desconhecimento de seu lugar na sociedade à consciência de sua situação real e objetiva, bem como ao seu conseqüente desejo de agir” (GONZÁLEZ, 1994, p.243). Isso ocorre com John. O personagem deixa o desconhecido e passa a ter consciência de sua situação. A partir disso, inicia-se a luta de John contra a sociedade de Londres.

Uma forma que ele encontra de lutar é evitando praticar atos valorizados por ela: “'O Selvagem', escreveu Bernard, 'recusa-se a tomar soma e parece muito aflito porque a mulher Linda, sua m..., vive em permanente fuga da realidade'” (HUXLEY, 2009, p.250). A forma de John se portar socialmente altera-se. Ele deixa de ser um indivíduo pacífico e começa a agir violentamente. Sendo assim, o personagem começa a cometer certos delitos. Um deles é a agressão a uma mulher que tentou seduzi-lo a praticar atos sexuais. Por ele seguir uma ideologia religiosa que desaprova a prática desses atos, John a agrediu como forma de reprimi-la:

O Selvagem tomou-lhe os pulsos, arrancou de seus ombros as mãos de Lenina e repeliu-a brutalmente. - Ai, você está me machucando, você... oh! - Ela calou-se de repente. O terror fizera-lhe esquecer a dor (HUXLEY, 2009, p.297).

A agressão de John pode ser considerada uma forma que o personagem utiliza para se revoltar contra a sociedade. Após a perda de sua mãe, a insatisfação do personagem com a sociedade se intensifica. Com isso, ele procura, agindo com violência, questionar a ideologia vigente nessa sociedade e alterá-la nos indivíduos:

- Mas vocês gostam de ser escravos? - dizia o Selvagem quando eles entraram no Hospital. Seu rosto estava rubro, seus olhos chamejavam de ardor e indignação. [...] A dor e o remorso, a compaixão e o dever, tudo estava agora esquecido e de algum modo absorvido num ódio intenso e irresistível àqueles monstros menos que humanos. - Vocês não querem ser livres, ser 
homens? Nem sequer compreendem o que significa ser homem, o que é liberdade? - A raiva tornava-o um orador fluente, as palavras ocorriam-lhe com facilidade, jorravam - Não compreendem? - insistiu, mas não obteve resposta (HUXLEY, 2009, p.325).

Sem resposta, John percebe que não há como mudar essa sociedade e se vê contaminado por ela. Procurando não receber mais influência da civilização, o personagem encontra como única solução o isolamento:

O Selvagem escolhera para seu eremitério o velho farol que se erguia sobre a crista da colina entre Puttenham e Elstead. A construção era de cimento armado e estava em excelentes condições - quase confortável demais, pensara o Selvagem, ao explorar o local pela primeira vez, quase excessivamente luxuosa e civilizada. Aplacou a consciência prometendo impor-se, como compensação, uma disciplina pessoal mais dura, purificações completas e rigorosas (HUXLEY, 2009, p.372).

Candido (1970) expõe que "o malandro espanhol termina sempre, ou numa resignada mediocridade, aceita como abrigo depois de tanta agitação, ou mais miserável do que nunca, no universo do desengano e da desilusão”. No caso de John, esse termina no universo do desengano e da desilusão. No seu isolamento, John encontra um espaço próprio. González (1994) ressalta que:

o pícaro é uma primeira manifestação de individualismo, que se traduz na procura de um espaço próprio, procura que - pela falta de solidariedade do pícaro - termina na solidão e não se redunda em qualquer projeto social.

O personagem não quer ter contato com outros indivíduos. O desejo dele é estar em solidão. Entretanto, até mesmo em seu espaço próprio, o personagem é incomodado por outros indivíduos, que procuram constantemente observar seus atos:

Atraídos pela fascinação do horror do sofrimento e, interiormente, impelidos pelo hábito da ação em comum, pelo desejo de unanimidade e comunhão, que o condicionamento neles implantara de forma tão indelével, os curiosos puseram-se a imitar o frenesi dos gestos do Selvagem, batendo uns nos outros, enquanto ele fustigava sua própria carne rebelde, ou aquela encarnação roliça da torpeza que se contorcia nas urzes a seus pés (HUXLEY, 2009, p.390).

John se torna um sujeito frustrado por em nenhum momento, independente do lugar, conseguir ter os seus desejos realizados. Isso culmina em seu suicídio:

Lentamente, muito lentamente, como duas agulhas de bússola sem pressa, os pés voltaram-se para a direita: norte, nordeste, leste, sudeste, sul, sul- 
sudoeste; depois se detiveram e, passados alguns segundos, recomeçaram a girar, com a mesma lentidão, para a esquerda. Sul-sudoeste, sul, sudeste, leste (HUXLEY, 2009, p.392).

\section{Conclusão}

Candido (1970) expõe a visão de Damasceno (1956 apud CANDIDO, 1970, p.67) de que "não há que considerar-se picaresco um livro pelo fato de nele haver um pícaro mais adjetival que substantival, mormente se a este livro faltam as marcas peculiares do gênero picaresco". Com base nesse relato de Candido e no estudo realizado, verifica-se que Admirável de Mundo Novo não se trata de uma obra do gênero pícaro, principalmente pelo fato de os aspectos desse gênero serem apresentados apenas no personagem John, o Selvagem.

Em sua busca de encontrar o seu espaço próprio e realizar os seus anseios, John traça o mesmo percurso de um personagem pícaro. Ele inicia na precariedade e na ingenuidade. Em seguida, a mercê da sorte, passa a ocupar um outro espaço. $O$ personagem deixa a inocência para agir com revolta e, assim como os demais pícaros, termina na mediocridade, o que culmina na desilusão e na solidão. A forma de reflexão do personagem é sempre relacionada a sua própria situação. $\mathrm{O}$ único aspecto que falta em John para torná-lo, de fato, um personagem pícaro é a malandragem.

Dessa forma, o que faz dele um anti-herói e não um herói? Massaud Moisés (2004) ressaltou a respeito dessa dúvida. Essa mesma dúvida surge ao tratar-se de John. Partindo das próprias afirmações de Moisés, o herói “caracteriza-se pela valentia, a coragem física e moral” (MOISÉS, 2004, p.219) o anti-herói

Não se define como a personagem que necessariamente carrega defeitos ou taras, ou comete delitos e crime, mas como a que possui debilidade ou indiferenciação de caráter, a ponto de assemelhar-se a muita gente. É 'o homem sem qualidades' (MOISÉS, 2004, p.28).

John não é dotado de valentia, ele possui debilidades, como a de ser um indivíduo isolado, não possuir seu próprio espaço e ser indiferente aos demais devido a suas ideologias. A única qualidade que pode ser considerada em John, para não afirmar que ele não possui nenhuma, é o de seguir seus ideais. Dessa forma, ele não intenciona o bem comum, mas sim alcançar seus próprios anseios, o que o caracteriza como um anti-herói.

\section{Referências}

CANDIDO, A. Dialética da malandragem. In: Revista do instituto de estudos brasileiros, $n^{\circ}$ 8, São Paulo: USP, 1970. p.67-89. Disponível em: 
http://ebookbrowsee.net/dialetica-malandragem-pdf-d437711300. Acesso em: 05 de junho de 2014.

GONZÁLEZ, M. M. A saga do anti-herói: estudo sobre romance picaresco espanhol e algumas de suas correspondências na literatura brasileira. São Paulo: Alexandria, 1994.

HUXLEY, Aldous. Admirável mundo novo. São Paulo: Globo, 2009.

MOISÉS, M. Dicionário de termos literários. $12^{a}$ ed. São Paulo: Cultrix, 2004.

Enviado: 28/11/2014

Aprovado: 02/03/2015 